\title{
PENGARUH PENGOLAHAN TANAH DAN PEMULSAAN TERHADAP KERAGAMAN DAN KELIMPAHAN NEMATODA PARASIT TUMBUHAN PADA PERIODE TANAM RATOON- I DI PERKEBUNAN TEBU PT GUNUNG MADU PLANTATIONS
}

\author{
Uswatun Hasanah, I Gede Swibawa \& Titik Nur Aeny \\ Jurusan Agroteknologi, Fakultas Pertanian Universitas Lampung \\ Jl. Prof. Soemantri Brodjonegoro, No. 1, Bandar Lampung 35145 \\ E-mail: uswtnhasanah04@gmail.com
}

\begin{abstract}
ABSTRAK
Penelitian ini bertujuan untuk mempelajari keragaman dan kelimpahan nematoda parasit tumbuhan akibat perlakuan sistem pengolahan tanah dan pemulsaan pada pertanaman tebu periode ratoon I. Penelitian dilaksanakan di lahan pertanaman tebu milik PT Gunung Madu Plantations dari April sampai dengan September 2012. Satuan percobaan berupa petak $25 \mathrm{~m}$ x $40 \mathrm{~m}$ dirancang menggunakan rancangan petak terbagi (split plot design) dengan sistem olah tanah sebagai petak utama dan pemulsaan sebagai anak petak, dengan lima ulangan (kelompok). Sistem olah tanah terdiri dari dua taraf, yaitu tanpa olah tanah dan olah tanah intensif. Pemulsaan terdiri dari 2 taraf, yaitu pemberian mulsa bagas 80 ton ha ${ }^{-1}$ dan tanpa mulsa. Sampel tanah diambil ketika tebu berumur 8 bulan dan 11 bulan, nematoda diekstraksi menggunakan metode penyaringan dan sentrifugasi menggunakan larutan gula dan diidentifikasi sampai pada tingkat genus berdasarkan ciri morfologinya. Hasil penelitian menunjukkan bahwa di lahan PT GMP ditemukan 34 genus nematoda dalam 6 ordo pada pertanaman tebu ratoon I. Jumlah genus dan indeks keragaman Shannon nematoda pada pertanaman tebu ratoon I tidak dipengaruhi oleh sistem olah tanah dan pemulsaan. Indeks keragaman Simpson nematoda pada pertanaman tebu ratoon I dengan perlakuan sistem olah tanah intensif tanpa pemulsaan lebih tinggi dibandingkan pada sistem tanpa olah tanah tanpa pemulsaan. Kelimpahan nematoda parasit tumbuhan pada pertanaman tebu ratoon I tidak dipengaruhi oleh perlakuan olah tanah dan pemulsaan. Kelimpahan nematoda parasit tumbuhan pada tebu ratoon I ketika umur 11 bulan lebih rendah daripada ketika umur 8 bulan.
\end{abstract}

Kata kunci : Nematoda parasit tumbuhan, pemulsaan, dan pengolahan tanah.

\section{PENDAHULUAN}

Tanaman tebu merupakan tanaman penghasil gula, batangnya mengandung air gula dengan kadar mencapai 20\% (Tim Penulis Penebar Swadaya, 1992). Pada umumnya budidaya tebu di Indonesia dilakukan secara intensif yang meliputi pengolahan tanah, irigasi, pengendalian gulma, pemupukan, dan pemanenan. PT GMP merupakan salah satu perusahan perkebunan tebu swasta besar di Lampung, sejak berdirinya perusahaan ini menerapkan pengolahan tanah secara intensif dalam budidaya tebunya. Belakangan ini, terindikasi bahwa pengolahan tanah tersebut menimbulkan masalah yaitu kerusakan tanah yang mengakibatkan penurunan produksi tebu. Untuk mengatasi masalah tersebut, PT GMP mulai melakukan kajian penerapan sistem olah tanah konservasi yaitu sistem tanpa olah tanah (TOT) dan pemulsaan. Dengan sistem TOT dan pemulsaan diharapkan akan terjadi peningkatan kesuburan. Pemberian mulsa merupakan salah satu komponen penting dalam sistem TOT. Mulsa adalah bahan atau material yang digunakan untuk menutupi permukaan tanah atau lahan. Pemberian mulsa memiliki keuntungan karena dapat meningkatkan aktivitas biota tanah yang berperan dalam memperbaiki sifat fisika dan kimia tanah (Soekardi, 1986).

Salah satu biota tanah penting pada pertanaman tebu adalah nematoda. Komunitas nematoda meliputi nematoda parasit tumbuhan dan nematoda hidup bebas. Nematoda hidup bebas berperan sebagai mikropredator, memakan jasad renik seperti bakteri, jamur dan ganggang yaitu organisme yang terlibat dalam jaringjaring makanan perombakan bahan organik tanah. Nematoda yang memakan jasad renik perombak dapat mencegah perombakan bahan organik yang berlangsung cepat (Dropkin, 1992). Sementara itu, nematoda parasit tumbuhan bersifat merugikan karena merusak perakaran tanaman. Pada populasi yang tinggi, serangan nematoda parasit tumbuhan dapat secara nyata menurunkan produksi tebu. Selain itu, akar tanaman yang luka akibat serangan nematoda parasit tumbuhan dapat menjadi jalan bagi serangan patogen tanaman lain seperti jamur dan bakteri sehingga kerusakan tanaman menjadi lebih parah.

Keragaman nematoda sangat tinggi pada pertanaman tebu dibandingkan dengan pada tanaman 
budidaya lainnya. Menurut Spaull dan dan Cadet (2005) lebih dari 310 spesies dalam 48 genus nematoda parasit tumbuhan diketahui berasosiasi dengan daerah perakaran tanaman tebu. Studi mengenai pengaruh pengolahan tanah dan pemulsaan pada pertanaman tebu belum banyak dilakukan. Diperkirakan bahwa penerapan sistem tanpa olah tanah dan pemulsaan pada pertanaman tebu akan mempengaruhi aktivitas nematoda. Penelitian ini bertujuan untuk mempelajari keragaman dan kelimpahan nematoda parasit tumbuhan akibat perlakuan sistem pengolahan tanah dan pemulsaan pada pertanaman tebu periode ratoon I. Informasi yang dihasilkan dari penelitian ini dapat melengkapi informasi tentang komunitas nematoda yang didapatkan dari hasil penelitian periode plant cane.

\section{BAHAN DAN METODE}

Penelitian ini merupakan bagian dari penelitian jangka panjang “ Studi Rehabilitasi Tanah" kerjasama Unila-PT GMP-Yokohama National University (YNU) yang dilaksanakan di Perkebunan Tebu PT. Gunung Madu Plantations (GMP), Lampung Tengah. Pengambilan sampel tanah dilakukan ketika periode tanaman tebu Ratoon- I dan ekstrasi serta analisis nematoda dilakukan di Laboratorium Hama dan Penyakit Tumbuhan, Fakultas Pertanian, Universitas Lampung. Penelitian dilakukan dari April - September 2012.

Perlakuan dalam penelitian ini disusun dalam Rancangan Percobaan Petak Terbagi (Split Plot Experimental Design) dengan lima blok sebagai ulangan. Petak utama adalah sistem olah tanah dan anak petak adalah pemulsaan. Sistem olah tanah terdiri dari dua perlakuan, yaitu sistem tanpa atau reduksi olah tanah $\left(\mathrm{T}_{0}\right)$ dan olah tanah intensif $\left(\mathrm{T}_{1}\right)$, sedangkan pemulsaan terdiri dari dua perlakuan, yaitu tanpa mulsa $\left(\mathrm{M}_{0}\right)$ dan pemberian mulsa bagas 80 ton $\mathrm{ha}^{-1}\left(\mathrm{M}_{1}\right)$. Pengolahan lahan dilakukan oleh pihak PT GMP yang dimulai dengan membagi lahan menjadi 20 petak percobaan sesuai dengan perlakuan dan ukuran tiap petaknya $25 \mathrm{~m}$ x $40 \mathrm{~m}$.

Pengambilan sampel tanah dilakukan bulan april ketika tebu berumur 8 bulan dan Juli 2012 saat tebu ratoon I berumur 11 bulan. Dari setiap petak percobaan, sampel tanah diambil pada 12 titik sub sampel melingkar dengan monolith sebagai pusatnya, 4 titik berjarak $3 \mathrm{~m}$ dari pusat dan 8 titik berjarak $3 \mathrm{~m}$ dari titik pertama (Susilo dan Karyanto, 2005). Ekstraksi nematoda dari tanah menggunakan metode penyaringan dan sentrifugasi dengan larutan gula terhadap $300 \mathrm{cc}$ sampel tanah (Gafur dan Swibawa, 2004). Nematoda difiksasi dengan larutan golden $\mathrm{X}$ sehingga nematoda berada pada larutan formalin 3\% dan suspensi nematoda dijadikan $10 \mathrm{ml}$. Kelimpahan nematoda dihitung dengan cara mengambil sekitar $3 \mathrm{ml}$, kemudian dituang ke cawan petri bergaris dan dihitung di bawah mikroskop stereo binokuler pada perbesaran 40 kali. Penghitungan dilakukan sampai seluruh suspensi habis. Identifikasi nematoda berdasarkan ciri-ciri morfologi dilakukan terhadap 100 nematoda yang diambil secara acak. Identifikasi nematoda sampai tingkat genus berpedoman pada buku Pictorial Key to Genera of Plant Parasitic Nematodes (Mai dan Lyon, 1975) dan Soil and Freshwater Nematodes (Goodey, 1963).

Untuk mengetahui pengaruh perlakuan, kelimpahan seluruh nematoda (nematoda parasit tumbuhan + nematoda hidup bebas) dan kelimpahan nematoda parasit tumbuhan dianalisis ragam pada taraf $5 \%$ atau $1 \%$. Untuk membandingkan kelimpahan nematoda parasit tumbuhan antarumur tanaman digunakan uji $\mathrm{T}$ taraf $1 \%$ atau $5 \%$. Keragaman nematoda yang dinyatakan dengan indeks Shannon dan Simpson's dianalisis ragam dan pemisahan nilai tengahnya menggunakan uji BNT pada taraf 5\%.

\section{HASIL DAN PEMBAHASAN}

Kelimpahan seluruh nematoda adalah kelimpahan nematoda parasit tumbuhan dan nematoda hidup bebas yang dinyatakan dalam individu per $300 \mathrm{cc}$ tanah. Analisis ragam menunjukkan bahwa pengolahan tanah dan pemulsaan serta interaksinya tidak berpengaruh nyata terhadap kelimpahan seluruh individu nematoda baik ketika tebu berumur 8 bulan maupun 11 bulan periode tanam ratoon I. Kelimpahan seluruh nematoda adalah 384 dan 573 individu per $300 \mathrm{cc}$ tanah masingmasing ketika tebu berumur 8 bulan dan 11 bulan.

Kelimpahan nematoda parasit tumbuhan adalah kelimpahan seluruh genus yang berperan sebagai parasit tumbuhan pada pertanaman tebu. Analisis ragam menunjukkan bahwa perlakuan olah tanah dan pemulsaan serta interaksinya tidak mempengaruhi kelimpahan nematoda parasit tumbuhan baik ketika tanaman tebu berumur 8 bulan maupun tebu 11 bulan. Pada Gambar 1 dapat dilihat bahwa kelimpahan nematoda parasit tumbuhan ketika tebu berumur umur 8 bulan pada perlakuan $\mathrm{T}_{0}$ sebesar 98,4 sedangkan pada $\mathrm{T}_{1}$ sebesar 102,2 individu per $300 \mathrm{cc}$. Untuk tebu umur 11 bulan kelimpahan nematoda parasit tumbuhan pada perlakuan $\mathrm{T}_{0}$ sebesar 84,4 dan pada $\mathrm{T}_{1}$ sebesar 88,8 individu per $300 \mathrm{cc}$ tanah. Apabila dilihat berdasarkan umur tanaman kelimpahan nematoda parasit tumbuhan ketika tebu berumur 8 bulan baik pada petak $\mathrm{T}_{0}$ maupun petak $\mathrm{T}_{1}$ sangat nyata $(\mathrm{P}<0,01)$ lebih tinggi daripada 
kelimpahan nematoda parasit tumbuhan ketika tebu berumur 11 bulan. Demikian pula pada petak $\mathrm{M}_{0}$ maupun petak $\mathrm{M}_{1}$, kelimpahan nematoda ini pada tebu umur 8 bulan sangat nyata $(\mathrm{P}<0,01)$ lebih tinggi daripada ketika tebu berumur 11 bulan (Gambar 2). Data ini mengindikasikan bahwa peningkatan umur tanaman tebu diikuti oleh penurunan kelimpahan nematoda parasit tumbuhan. Pada Gambar 2 tampak bahwa ketika tebu berumur umur 8 bulan kelimpahan nematoda pada perlakuan $\mathrm{M}_{0}$ sebesar 100,8 sedangkan pada $\mathrm{M}_{1}$ sebesar 99,8 individu per $300 \mathrm{cc}$. Untuk tebu umur 11 bulan kelimpahan nematoda parasit tumbuhan pada perlakuan $\mathrm{M}_{0}$ sebesar 87,9 dan pada $\mathrm{M}_{1}$ sebesar 85,3 individu per 300 cc tanah.

Hasil penelitian ini menunjukan bahwa tanpa olah tanah dan pemberian serasah bagas pada pertanaman tebu tidak mempengaruhi kelimpahan nematoda parasit tumbuhan. Diperkirakan bagas adalah serasah yang karakteristikya berbeda dengan serasah sisa tanaman seperti daun dan ranting, karena serasah bagas merupakan serasah yang kandungan seratnya tinggi dan tidak megandung gula. Swibawa (2010) juga melaporkan bahwa perlakuan tanpa olah tanah yang diberi mulsa pada pertaman jagung tidak mempengaruhi kelimpahan nematoda parasit tumbuhan.

Apabila dilihat dari komposisi komunitas nematoda maka tampak bahwa pertanaman tebu di PT GMP didominasi oleh nematoda hidup bebas. Ketika tebu berumur 8 bulan ditemukankan 30 genus terdiri dari 12 genus nematoda parasit tumbuhan dan 18 genus nematoda hidup bebas. Kelimpahan genus nematoda hidup bebas sebesar $74 \%$ sisanya sebanyak $26 \%$ adalah

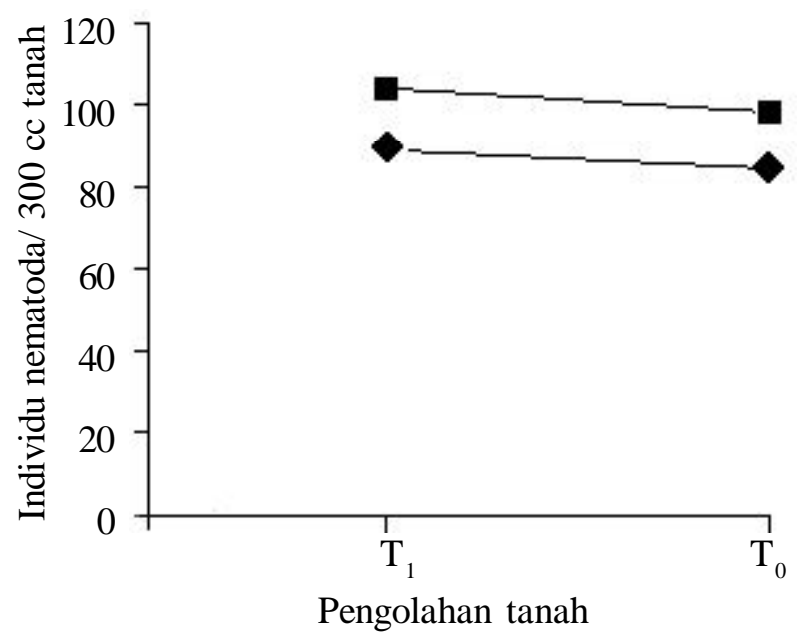

Gambar 1. Kelimpahan nematoda parasit tumbuhan pada pertanaman tebu dengan olah tanah intensif $\left(\mathrm{T}_{1}\right)$, dan tanpa olah tanah $\left(\mathrm{T}_{0}\right)$. $=8$ bulan, $\boldsymbol{\top}=11$ bulan nematoda parasit tumbuhan. Ketika tebu berumur 11 bulan ditemukan 25 genus nematoda yang terdiri dari 15 genus nematoda parasit tumbuhan dan 10 genus nematoda hidup bebas. Ketika tanaman tebu berumur 11 bulan, walaupun jumlah genus nematoda parasit tumbuhan lebih tinggi daripada nematoda hidup bebas, namun kellimpahan nematoda parasit tumbuhan hanya $15 \%$ dari seluruh individu dalam komunitas nematoda (Gambar 3). Berdasarkan data ini tampak bahwa pada pertanaman tebu terjadi penurunan kelimpahan nematoda parasit tumbuhan seiring dengan peningkatan umur tanaman. Menurut Cadet dan Spaull (1985 dalam Spaull dan Cadet 2005) puncak populasi nematoda ektoparasit pada pertanaman tebu plant cane terjadi pada 9 BST (bulan setelah tanam) dan terjadi penurunan pada bulan berikutnya, sedangkan pada tanaman tebu ratoon $\mathrm{I}$ puncak populasi nematoda tersebut terjadi pada saat umur 10 bulan. Pada penelitian ini terjadi kecendrunngan yang sama, namun populasi nematoda parasit tumbuhan yang tinggi terjadi pada saat tebu berumur 8 bulan.

Dua genus nematoda memiliki kelimpahan relatif tertinggi baik saat tanaman berumur 8 bulan atau pun saat tanaman berumur 11 bulan. Genus nematoda tersebut yaitu Hemicriconemoides dan Hoplolaimus. Kelimpahan relatif Hemicriconemoides saat tanaman tebu umur 8 bulan yaitu 23,55\% dan pada 11 bulan yaitu 26,30\%, sedangkan kelimpahan relatif Hoplolaimus pada 8 bulan dan 11 bulan masing-masing yaitu 24,7\% dan 25,89\% (Tabel 1). Diketahui bahwa kedua genus nematoda tersebut merupakan nematoda parasit tumbuhan yang berpotensi menjadi hama pada tanaman tebu.

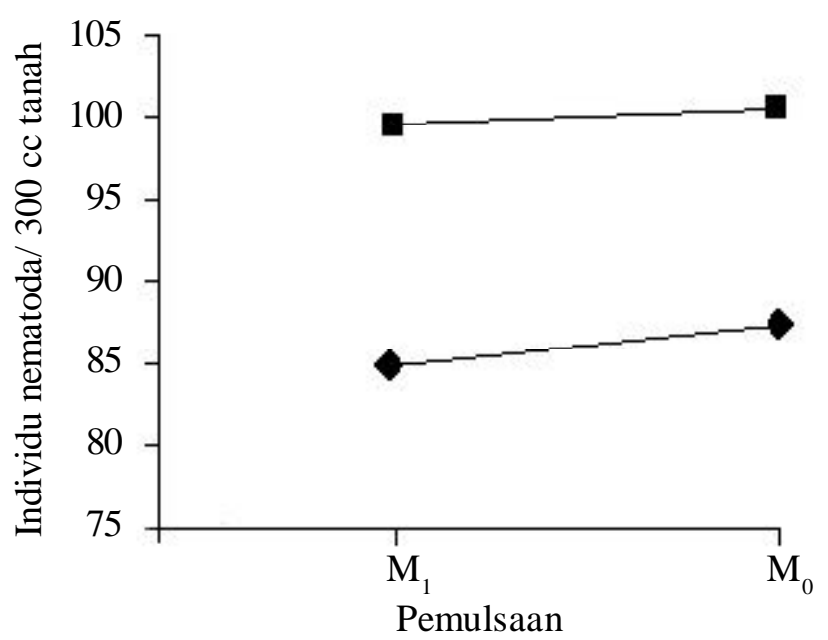

Gambar 2. Kelimpahan nematoda parasit tumbuhan pada pertanaman tebu dengan pemberian mulsa $\left(\mathrm{M}_{1}\right)$ dan tanpa mulsa $\left(\mathrm{M}_{0}\right)$. $\boldsymbol{\square}=8$ bulan, $\bullet=11$ bulan 


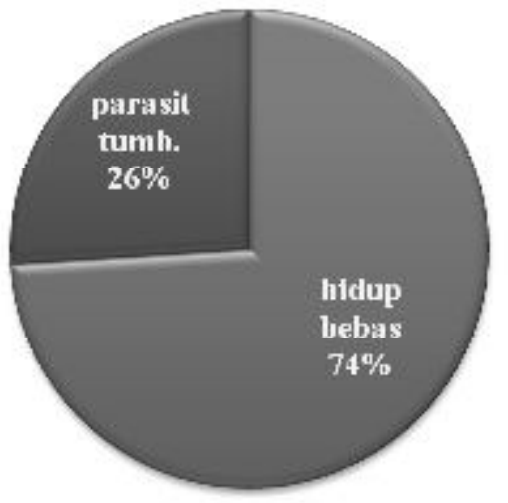

8 bulan

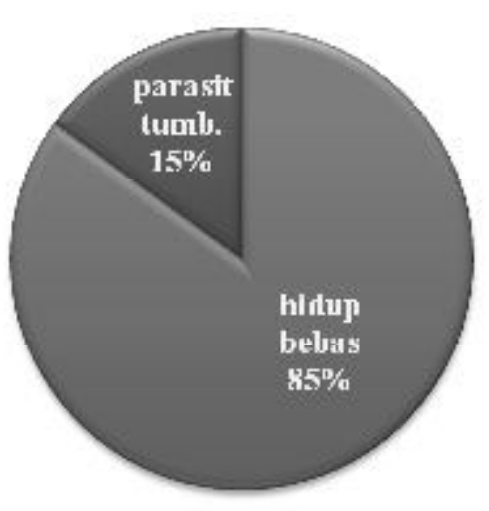

11 bulan

Gambar 3. Proporsi nematoda parasit tumbuhan ketika tebu berumur 8 bulan dan 11 bulan saat periode tanam ratoon $I$.

Menurut Singh (1967 dalam Spaull dan Cadet 1995) Hoplolaimus indicus merupakan salah satu nematoda parasitik tumbuhan yang paling banyak tersebar luas dan berasosiasi dengan berbagai pertanaman di India. Spesies Hoplolaimus merupakan nematoda ektoparsitik pada akar tanaman tebu, seperti $H$. indica dan $H$. columbus keduanya dilaporkan dapat menghambat pertumbuhan normal dan perkembangan akar tanaman tebu. Gejala serangan nematoda tersebut adalah luka nekrotik berwarna merah-ungu pada akar. luka tersebut terlihat melingkari akar ketika terjadi serangan berat (Singh dan Mirsa, 1976 dalam Spaull dan Cadet, 1995).

Menurut Spaull dan Cadet (1995) genus Pratylenchus juga merupakan nematoda parasit tumbuhan yang dapat menimbulkan kerusakan serius pada tanaman tebu di dunia. Ambang kerusakan ekonomi Pratylenchus pada pertanaman tebu di Australia berkisar 250 individu nematoda per $200 \mathrm{~g}$ tanah. Dalam penelitian ini, saat tanaman berumur 8 bulan kelimpahan Pratylenchus yaitu 204,21 nematoda per $300 \mathrm{cc}$ tanah dan saat tanaman berumur 11 bulan kelimpahan Pratylenchus menurun menjadi 133,08 nematoda per $300 \mathrm{cc}$ tanah. Artinya, kelimpahan nematoda Pratylenchus di lahan pertanaman PT GMP masih rendah dan belum mencapai aras yang menimbulkan kerusakan secara ekonomi.

Keragaman nematoda diukur dari jumlah genus dan indeks keragaman Shannon serta indeks keragaman Simpsons. Nematoda yang ditemukan pada lahan pertanaman tebu PT Gunung Madu Plantation saat tanaman tebu berumur 8 dan 11 bulan periode tanam ratoon I terdiri dari 34 genus yang termasuk ke dalam 6 ordo dan 6 kelompok makan (Tabel 3). Enam ordo dari nematoda yang ditemukan adalah Tylenchida, Rhabditida,Dorylaimida, Enoplida, Mononchida, dan
Chromadorida. Pada saat tebu berumur 8 bulan ditemukan 30 genus dan pada saat 11 bulan ditemukan 25 genus nematoda. Sebanyak 15 genus adalah nematoda parasit tumbuhan yang di temukan antara lain Criconema, Helicotylenchus, Hemicriconemoides, Rotylencoides, Hoplolaimus, Pratylenchus, Radopoloides, Radopholus, Scutellonema, Tetylenchus, Trichodorus, Tylenchus, Tylenchorhynchus, Longidorella, Xiphinema. Spaull dan Cadet (1995) menyebutkan bahwa nematoda parasit tumbuhan yang banyak ditemukan berasosiasi dengan tanaman tebu yaitu, Criconemoides, Pratylenchus, Hoplolaimus, Helicotylenchus, Tylenchorhynchus, Xiphinema, Meloidogyne, Paralongidorus, Rotylenchus, Hemicycliophora, dan Scutellonema

Keragaman komunitas seluruh nematoda diukur dari jumlah genus, indeks keragaman Shannon dan indeks keragaman Simpson. Analisis ragam menunjukkan bahwa pengolahan tanah dan pemulsaan serta interaksi diantara keduanya tidak berpengaruh nyata $(\mathrm{P}>0,05)$ terhadap jumlah genus. Namun ketika 8 bulan interaksi pengolahan tanah dan pemulsaan berpengaruh nyata terhadap indeks keragaman Simpson dan saat tebu berumur 11 bulan kelompok berpengaruh nyata terhadap indeks keragaman Shannon (Tabel 1). Indeks keragaman Shannon mengukur keragaman berdasarkan jenis yang umum sehingga jika nilai indeks keragaman ini tinggi maka keragaman jenis (genus) nematoda tinggi, sedangkan indeks keragaman Simpson lebih mengukur keragaman dan jenis yang langka, apabila nilai indeks keragaman ini rendah maka terdapat suatu jenis nematoda yang dominan (Krebs, 1985).

Pada Tabel 2 tampak bahwa perlakuan olah tanah intensif tanpa mulsa memiliki indeks keragaman Simpson sebesar 0,86 nyata lebih tinggi daripada indeks keragaman Simpson pada petak tanpa olah tanah tanpa 
Tabel 1. Nilai F hitung analisis ragam jumlah genus, indeks Shannon, dan indeks Shimpson komunitas nematoda pada pertanaman tebu di PT GMP umur 8 dan 11 bulan

\begin{tabular}{lcccccc}
\hline \multirow{2}{*}{ Perlakuan } & \multicolumn{2}{c}{ Jumlah Genus } & \multicolumn{2}{c}{ Indeks Shannon } & \multicolumn{2}{c}{ Indeks Simpsons } \\
\cline { 2 - 7 } & $8 \mathrm{BST}$ & $11 \mathrm{BST}$ & $8 \mathrm{BST}$ & $11 \mathrm{BST}$ & $8 \mathrm{BST}$ & $11 \mathrm{BST}$ \\
\hline Kel ompok & $4,30 \mathrm{tn}$ & $1,00 \mathrm{tn}$ & $0,84 \mathrm{tn}$ & $11,89^{*}$ & $1,07 \mathrm{tn}$ & $1,01 \mathrm{tn}$ \\
Olah tanah (T) & $1,25 \mathrm{tn}$ & $1,44 \mathrm{tn}$ & $0,47 \mathrm{tn}$ & $2,95 \mathrm{tn}$ & $2,45 \mathrm{tn}$ & $0,91 \mathrm{tn}$ \\
Mulsa (M) & $4,90 \mathrm{tn}$ & $0,05 \mathrm{tn}$ & $0,80 \mathrm{tn}$ & $0,09 \mathrm{tn}$ & $0,01 \mathrm{tn}$ & $0,28 \mathrm{tn}$ \\
interaksi (T x M) & $0,83 \mathrm{tn}$ & $0,45 \mathrm{tn}$ & $0,01 \mathrm{tn}$ & $0,04 \mathrm{tn}$ & $6,28 *$ & $0,18 \mathrm{tn}$ \\
\hline
\end{tabular}

Keterangan: $\mathrm{tn}=$ tidak berbeda nyata dan $*$ = berbeda nyata menurut uji BNT pada $\alpha_{0,05} . \mathrm{T}=$ petak utama dan $\mathrm{M}=$ anak petak.

Tabel 2. Pengaruh sistem olah tanah dan pemulsaan terhadap indeks keragaman Simpson komunitas nematoda ketika tanaman tebu berumur 8 bulan

\begin{tabular}{ccc}
\hline \multirow{2}{*}{ Sistem Olah Tanah } & \multicolumn{2}{c}{ Mulsa } \\
\cline { 2 - 3 } & Tanpa Mulsa & Mulsa bagas 80 ton ha $^{-1}$ \\
\hline Tanpa Olah Tanah & $0,69 \mathrm{a}$ & $0,79 \mathrm{a}$ \\
& $\mathrm{A}$ & $\mathrm{A}$ \\
Olah Tanah Intensif & $0,86 \mathrm{a}$ & $0,75 \mathrm{a}$ \\
& $\mathrm{B}$ & $\mathrm{A}$ \\
\hline
\end{tabular}

BNT 5\%

0,15

Keterangan : Angka yang diikuti huruf sama tidak berbeda nyata menurut uji BNT pada $\alpha_{0,05}$. Notasi huruf besar menerangkan data arah vertikal dan huruf kecil menerangkan data arah horizontal.

mulsa yaitu 0,69. Pada perlakuan tanpa olah tanah dengan mulsa, indeks keragaman ini sebesar 0,79, tidak nyata berbeda dengan indeks keragaman Simpson pada petak dengan perlakuan olah tanah intesif yang diberi mulsa yaitu 0,75 . Dari data ini tampak bahwa pemberian mulsa tidak berpengaruh nyata terhadap indeks keragaman Simpson baik untuk olah tanah intensif maupun untuk tanpa olah tanah. Pada petak yang tidak diberi mulsa, perlakuan olah tanah intensif dapat meningkatkan indeks keragaman Simpson, namun tidak untuk petak yang diberi mulsa.

\section{KESIMPULAN}

Kesimpulan dari hasil penelitian ini adalah ditemukan 34 genus nematoda dalam 6 ordo pada pertanaman tebu ratoon I. Jumlah genus dan indeks keragaman Shannon nematoda pada pertanaman tebu ratoon I tidak dipengaruhi oleh sistem olah tanah dan pemulsaan. Indeks keragaman Simpson nematoda pada pertanaman tebu ratoon I dengan perlakuan sistem olah tanah intensif tanpa pemulsaan lebih tinggi dibandingkan pada sistem tanpa olah tanah tanpa pemulsaan. Kelimpahan nematoda parasit tumbuhan pada pertanaman tebu ratoon I tidak dipengaruhi oleh perlakuan olah tanah dan pemulsaan. Kelimpahan nematoda parasit tumbuhan pada tebu ratoon I ketika umur 11 bulan lebih rendah daripada ketika umur 8 bulan.

\section{SANWACANA}

Ucapan terima kasih disampaikan kepada PT GMP Lampung dan Yokohama National Unversity Jepang yang telah memberikan izin dan dana untuk dapat melakukan penelitian.

\section{DAFTAR PUSTAKA}

Dropkin V. H. 1992. Introduction to Plant Nematology. Departement of Plant Pathology University of Missouri, Columbia. Second Edition.

Gafur, A dan IG. Swibawa. 2004. Methods in Nematodes and Soil Microbe Research for Below-ground Biodiversity Assessment in F. X. Susilo, A. Gafur, M. Utomo, R. Evizal, S. Murwani, IG. Swibawa (eds.), Conservation and Sustainable Management of Below-ground Biodiversity in Indonesia. Universitas Lampung. P. 117-123. 
Tabel 3. Genus nematoda, kelompok makan, dan kelimpahan relatif (\%) nematoda yang ditemukan pada pertanaman tebu PT GMP umur 8 dan 11 bulan

\begin{tabular}{|c|c|c|c|c|}
\hline \multirow[t]{2}{*}{ No } & \multirow[t]{2}{*}{ Ordo dan Genus Nematoda } & \multirow[t]{2}{*}{ Kelompok Makan* } & \multicolumn{2}{|c|}{ Kelimpahan Relatif (\%) } \\
\hline & & & 8 bulan & 11 bulan \\
\hline & I. Ordo Tylenchida & & & \\
\hline 1 & Aphelenchus & 2 & 1,33 & 0,19 \\
\hline 2 & Aphelencoides & 2 & 0,88 & 0,38 \\
\hline 3 & Criconema & 3 & 0,34 & 0,09 \\
\hline 4 & Helicotylenchus & 3 & 2,65 & 4,60 \\
\hline 5 & Hemicriconemoides & 3 & 23,55 & 26,30 \\
\hline 6 & Rotylencoides & 3 & - & 0,09 \\
\hline 7 & Hoplolaimus & 3 & 24,73 & 25,89 \\
\hline 8 & Pratylenchus & 3 & 9,78 & 6,31 \\
\hline 9 & Radopoloides & 3 & - & 0,09 \\
\hline 10 & Radopholus & 3 & 1,33 & 0,71 \\
\hline 11 & Scutellonema & 3 & 5,51 & 6,73 \\
\hline 12 & Tetylenchus & 3 & 0,10 & 0,14 \\
\hline 13 & Trichodorus & 3 & 0,74 & 0,47 \\
\hline 14 & Tylenchus & 3 & 0,15 & 1,04 \\
\hline \multirow[t]{2}{*}{15} & Tylenchorhynchus & 3 & 3,20 & 1,52 \\
\hline & II. Ordo Rhabditida & & & \\
\hline 16 & Pelodera & 1 & - & 0,05 \\
\hline 17 & Dolichorhabdit is & 1 & 0,34 & 0,09 \\
\hline 19 & Mesorhabditis & 1 & 0,15 & - \\
\hline 20 & Rhabditis & 1 & 19,66 & 16,12 \\
\hline \multirow[t]{2}{*}{21} & Cruznema & 1 & 0,10 & - \\
\hline & II I. Ordo Dorylaim ida & & & \\
\hline 22 & Lon gidorel la & 3 & 0,10 & 0,09 \\
\hline 23 & Xiphinema & 3 & 4,77 & 5,69 \\
\hline 24 & Labronema & 4 & 0,10 & 0,05 \\
\hline 25 & Aporcelaimus & 4 & 0,05 & - \\
\hline \multirow[t]{2}{*}{26} & Lordellonema & 5 & 0,05 & - \\
\hline & IV. Ordo Enoplida & & & \\
\hline 27 & Cryptonchus & 1 & 0,15 & 0,05 \\
\hline \multirow[t]{2}{*}{28} & Ironus & 5 & 0,05 & - \\
\hline & V. Ordo Mononchida & & & \\
\hline 29 & Anatonchus & 5 & 0,05 & - \\
\hline 30 & Miconchus & 5 & 0,29 & 0,19 \\
\hline 31 & Mononchus & 5 & 0,15 & 0,09 \\
\hline 32 & Judonchulus & 5 & 0,05 & - \\
\hline \multirow[t]{2}{*}{33} & Cobbonchus & 5 & - & 0,05 \\
\hline & VI. Ordo Chromadorida & & & \\
\hline 34 & Prochromadora & 6 & 0,10 & - \\
\hline
\end{tabular}

Keterangan: *Kelompok Makan (Yeates et al., 1993: 1 = Pemakan bakteri, 2 = Pemakan jamur, 3 = Parasit Tumbuhan, 4 = Omnivora, 5 = Predator, $6=$ Pemakan alga). 
Goodey, J.B. 1963. Soil and Freshwater Nematodes. Methuen CO. LTD. London. $544 \mathrm{hlm}$

Krebs, C. J. 1985. Ecology: The Experimental Analysis of Distribution an Abundance. Third edition. Harper and Row Publisher. New York.

Mai, W. F dan H. H. Lyon. 1975. Pictorial Key to Genera of Plant Parasitic Nematodes. Comstock Publishing Associates, Cornell University Press.

Soekardi. 1986. Pembukaan Lahan dan Pengolahan Tanah. Penunjang Pembangunan Nasional, Jakarta.

Spaull, V. W. dan P. Cadet. 1995. Nematoda Parasitik Pada Tanaman Tebu dalam M. Luc, R. A. Sikora dan J. Bridge (eds). Plant Parasite Nematodes in Subtropical and Tropical Agriculture diterjemahkan oleh Supratoyo. Nematoda Parasitik Tumbuhan di Pertanian Tropik dan Subtropik. Gadjah Mada University Press. Yogyakarta. P. $621-664$.
Spaull, V. W. dan P. Cadet. 2005. Nematode Parasities of Sugarcane in M. Luc, R. A. Sikora dan J, Bridge (eds). Plant Parasitic Nematodes in Subtropical and Tropical Agriculture, Second Edition. CAB International. UK. P. 645-647.

Susilo, F. X. dan A. Karyanto. 2005. Methods for Assessment of Below-Ground Biodiversity In Indonesia. Universitas Lampung.

Swibawa, I. G. 2010. Komunitas nematoda tanah pada lahan jagung setelah 23 tahun penerapan sistem budidaya tanpa olah tanah secara terus menerus. Prosiding Seminar Nasional Keragaman Hayati Tanah-1. Bandar Lampung. P. 147-161.

Tim Penulis Penebar Swadaya. 1992. Pembudidayaan Tebu di Lahan Sawah dan Tegalan. Penebar Swadaya. Jakarta.

Yeates, G. W., T. Bongers, R. G. M. De Goed, D. W. Freckman, dan S. S. Georgieva. 1993. Feeding habits in soil nematode families and genera-an outline for soil ecologist. Journal of Nematology. 25(3):315-331. 